\title{
Análise do Relacionamento entre a Contabilidade Gerencial e o Processo de Planejamento das Organizações Brasileiras
}

\author{
Fábio Frezatti \\ Reinaldo Guerreiro \\ Andson Braga de Aguiar \\ Maria Aparecida Gouvêa
}

\section{RESUMO}

Este estudo tem por objetivo investigar a existência de relacionamento entre os perfis da contabilidade gerencial e os perfis de planejamento de empresas brasileiras por meio de uma pesquisa de campo efetuada durante o ano de 2002, entre as empresas médias e grandes do ambiente empresarial brasileiro. A amostra foi obtida a partir da abordagem probabilística, dentro de um universo de 2.281 empresas. O construto levou em conta os avanços conceituais disponíveis, a aplicação do AHP (Analytic Hierarchy Process) e, através da técnica estatística de cluster analysis, os atributos da contabilidade gerencial das entidades foram agrupados em três diferentes perfis, sendo posteriormente aplicado o teste da mediana, com o objetivo de testar a significância estatística de tais diferenças. Como conclusão, pode-se afirmar que os perfis da contabilidade gerencial têm relacionamento com os perfis de aderência conceitual do planejamento estratégico e orçamento das entidades analisadas.

Palavras-chave: contabilidade gerencial; planejamento estratégico; orçamento.

\begin{abstract}
This study aims to examine if there exists a relation between Brazilian companies' management accounting and planning profiles, by means of a field research that was carried out in 2002 among Brazilian medium and large-sized companies. Probabilistic sampling was used in a universe of 2,281 companies. The construct considered the available conceptual advances and the application of the AHP - Analytic Hierarchy Process. By means of the statistical cluster analysis technique, the entities' management accounting attributes were grouped into three different profiles, after which the median test was applied to test the statistical significance of these differences. In conclusion, it can be affirmed, in the entities under analysis, the management accounting profiles are related to the profiles of conceptual adherence to strategic and budget planning.
\end{abstract}

Key words: management accounting; strategic planning; budgeting. 


\section{INTRODUÇÃO}

Muito embora o ambiente empresarial, desde longa data, se tenha mostrado volátil e, muitas vezes, imprevisível, nas últimas décadas passou por mudanças significativas, tornando a gestão mais complexa. Como consequiência, passa a existir maior necessidade de defesa e busca da competitividade, o que, para os setores menos protegidos, se torna ameaça à sobrevivência. Dentro desse contexto, Ansoff (1991) considerou que, para a maioria das empresas, não seria suficiente o retorno aos 'fundamentos históricos' da administração, mas o desenvolvimento e o domínio de novas maneiras de administrar. Dentro da abordagem da gestão, o planejamento tem evoluído e foi questionado ao longo do tempo, em decorrência tanto das suas limitações como também das expectativas inadequadas dos usuários. A postura de Ansoff na década de 80 foi marco significativo para essa área de conhecimento, referindo-se ao processo de planejamento das empresas, que compreende a divisão em planejamento estratégico e planejamento tático. O planejamento estratégico surge exatamente como um dos fundamentos, identificados por Ansoff, que permitiriam às empresas se defrontarem e lidarem com o ambiente. Welsch, Hilton e Gordon (1988, p. 11) caracterizam planejamento estratégico como aquele realizado pela cúpula da entidade, com horizonte de longo prazo, cujo enfoque reside "[...] nos objetivos e estratégias globais da empresa; afeta todas as funções gerenciais; envolve consequiências abrangentes e de longo prazo." Por sua vez, o planejamento tático, caracterizado pelo orçamento, só existe para implementar o primeiro.

Ainda que o planejamento estratégico esteja voltado essencialmente para o lado externo da entidade, a sua implementação e controle dependem da contabilidade gerencial, que proporciona condições da utilização do orçamento e do controle orçamentário nas entidades. Significa dizer que a materialização do planejamento estratégico ocorre por meio dos instrumentos táticos, sem os quais as decisões de longo prazo não se transformam em algo concreto; dessa maneira, a contabilidade gerencial se apresenta como recurso válido e importante no sentido de apoio ao processo decisório e do controle por meio do fornecimento de informações úteis aos gestores. Assim, em situação em que a contabilidade gerencial esteja estruturada, permitindo que o planejamento estratégico seja disponibilizado e refletido através do orçamento, ela será um elemento significativo para que o processo de planejamento seja implementado e mantido; por outro lado, seria possível identificar uma situação em que o planejamento estratégico poderia ser desenvolvido sem chances de implementação pelo fato de que a entidade não teria o orçamento e o controle orçamentário relativamente 
estruturados a partir da contabilidade gerencial. Embora a associação entre contabilidade gerencial e planejamento estratégico possa parecer evidente, não foi possível constatar, por meio da bibliografia consultada, qualquer estudo que trouxesse evidências empíricas que validassem essa tese.

Nessas condições, a análise da existência de relacionamento entre planejamento estratégico e estrutura da contabilidade gerencial, assim como a identificação de quais atributos da contabilidade gerencial estariam associados à existência do processo de planejamento da empresa, se constituem em algo útil para a organização. Esse é o foco da pesquisa que tem como questão orientadora o seguinte: existe alguma associação entre a estrutura de atributos da contabilidade gerencial utilizada nas organizações brasileiras de médio e grande porte e a sua aderência conceitual no desenvolvimento do planejamento?

Algumas definições operacionais são necessárias para o andamento da análise.

- Associação é entendida como existência de relação significativa, seja positiva seja negativa, entre as variáveis consideradas: contabilidade gerencial e planejamento.

. Estrutura de atributos da contabilidade gerencial, descrita em tópico específico.

- Aderência conceitual, por sua vez, significa que a entidade adota artefatos definidos na literatura da área, sendo aceito que o faça em diferentes níveis de intensidade e combinações de componentes. Este aspecto vai ser expresso de maneira mais detalhada na estrutura do construto através do modelo consolidado por Moores e Yuen (2001).

- Organização brasileira de médio e grande porte foi definida a partir do conceito de faturamento anual do Banco Nacional de Desenvolvimento Econômico-Social, BNDES.

- Planejamento deve ser entendido no sentido amplo, ou seja, incluindo o planejamento estratégico e tático.

\section{REVISÃo dA Literatura}

Tendo em vista a necessidade de estruturação da base conceitual, a revisão da literatura vai-se prender às seguintes demandas: processo de planejamento estratégico, relacionamento do planejamento estratégico com o tático, 


\section{relacionamento da contabilidade gerencial com o processo de planejamento e atributos da estrutura da contabilidade gerencial.}

\section{O Processo de Planejamento Estratégico}

Ansoff (1991, p. 20) afirma que o planejamento estratégico deveria oferecer respostas a duas necessidades, a saber:

- Necessidade de preparar a empresa para um futuro que não seria simples projeção do passado; e

- Necessidade de preparar a empresa de maneira abrangente e sistemática.

Mais recentemente, Delmar e Shane (2003, p. 1167) mencionam que o planejamento proporciona os seguintes benefícios de novos empreendimentos: facilita a tomada de decisão mais rápida ao identificar a ausência de informações, sem requerer o comprometimento de recursos, fornece ferramentas para administrar o fornecimento e demanda de recursos de uma maneira que evita o gargalo indevido de tempo e identifica a sequiência de ações para alcançar metas mais amplas de modo oportuno.

Steiner (1979), Sharplin (1985), Ansoff (1991), Oliveira (1994), Fischmann e Almeida (1993) trataram a figura do planejamento estratégico e concordam que objetivos devam ser fixados e, em alguma dimensão, quantificados. Por sua vez, Lenz como citado em Liedtka (2000, p. 204) identifica os principais problemas da abordagem tradicional do planejamento estratégico: (1) tenta criar uma ciência do planejamento com sua subseqüente perda de criatividade; (2) enfatiza os números de maneira excessiva; e (3) incorpora, predominantemente, técnicas simples e aplicadas de forma não apropriada. Adicionalmente, O'Regan e Ghobadian (2002, p. 426) identificam algumas barreiras à implementação do planejamento estratégico formal, dentre elas a disponibilidade de informação relevante e adequada, ou seja, "a disponibilidade de informação relevante é central para o processo de planejamento estratégico", em especial, para empresas que o empregam formalmente. Nesse sentido, Rogers e Bamford (2002, p. 205) enfatizam: "Tem sido sugerido que a questão organizacional, chave no futuro, será o gerenciamento da informação [...]". Em seguida, esses autores constatam que o "[...] processo de planejamento estratégico deve enfatizar os tipos de informações que corroboram a orientação estratégica da empresa" e afirmam: "Nenhum processo requer mais coordenação e entrada de informações que o processo de planejamento de uma organização." 
Levando-se em conta que, no planejamento estratégico, a perspectiva básica, referente às informações relevantes, surge em decorrência das questões externas à entidade, muitas vezes essa perspectiva acaba sendo a única que a empresa considera, sem incluir as informações internas da organização.

O planejamento estratégico foi associado com a obtenção de lucratividade superior e, em função desse aspecto, desde o final da década de 60, tem sido empregado pelas empresas que buscam obter melhor desempenho (Pearce, Freeman, \& Robinson, 1987, p. 658). No entanto diversas pesquisas têm constatado resultados divergentes, quando analisam o relacionamento entre planejamento estratégico e desempenho (Andersen, 2000; Armstrong, 1982; Glaister \& Falshaw, 1999; Rogers \& Bamford, 2002). Brock e Barry (2003, p. 544) destacam que, para alguns autores, a divergência desses resultados decorre, dentre outros, da inconsistência na operacionalização do significado de planejamento, de técnicas inválidas de mensuração e desconsideração de influências contextuais; para outros autores, tal divergência decorre da fraqueza dos dados contábeis. Peel e Bridge (1998, p. 853) estão entre os que afirmam ser a utilização de medidas de resultado, oriundas dos dados contábeis, uma razão potencial para a referida divergência. Tal fato decorre, como observam Bracker e Pearson (1986, p. 505), de duas desvantagens das medidas de desempenho baseadas na contabilidade: (1) falta de homogeneidade dos dados e (2) não disponibilidade de dados para pequenas firmas.

Uma conseqüência dos resultados divergentes, em especial dos resultados que não apresentam associação positiva entre planejamento estratégico e desempenho, é que "tem havido uma tendência de não enfatizar o papel do planejamento estratégico [...]" (Andersen, 2000, p. 184). Em outras palavras, quer seja por ausência de informações quer pela inadequação, a contabilidade gerencial pode estar contribuindo para o enfraquecimento do planejamento estratégico das empresas. De acordo com Ansoff, Declerck e Hayes (1976, pp. 1-2), a redução de ênfase na utilização do planejamento estratégico decorre de suas limitações, que são as seguintes:

- Enfatiza o problema das ligações externas, supondo que a configuração interna da organização permanecerá essencialmente estável.

- Interessa-se principalmente pela solução de problemas, determinando as novas ligações preferidas com o ambiente, supondo que a implementação e controle seguirão como atividades secundárias.

- As variáveis incluídas na análise são exclusivamente tecnológicas, econômicas e baseadas na informação. As dinâmicas sociais e políticas, tanto dentro quanto fora da organização, são assumidas como sendo irrelevantes e sem efeitos. 
. [...] é essencialmente cartesiano em sua abordagem, o que significa que aquilo que se planeja espera-se que ocorra.

Levando em conta a evolução histórica, Grant (2003) percebe que os sistemas de planejamento das décadas de 70 e 80 eram altamente protocolares em termos de documentação, apresentações formais, ênfase em técnicas e análises quantitativas e o papel central era dos planejadores. Contudo, na segunda metade da década de 90, sistemas de planejamento eram muito mais informais: havia menos ênfase em documentos escritos, planos estratégicos mais resumidos e enfoque voltado mais para uma discussão aberta do que a formalização de seus componentes.

Em síntese, o fluxo de informações emerge como elemento importante no processo de formação de estratégias, em especial no processo de planejamento estratégico e, por consequiência, no desempenho de uma empresa (Ansoff, 1997, p. 23; Steiner, 1979, p. 20).

Os componentes do processo de planejamento estratégico que identificam o perfil das empresas são aqueles especificados por Fischmann e Almeida (1993): visão, missão, objetivos de longo prazo, cenários e planos operacionais.

\section{O Relacionamento do Planejamento Estratégico com o Tático}

Steiner (1979, pp. 13-15), a partir de quatro pontos de vista, considera que o conceito de planejamento estratégico:

. está relacionado com as conseqüências futuras das decisões correntes;

. é processo que se inicia com a colocação dos objetivos organizacionais, para se definirem em seguida as estratégias e políticas com que alcançá-los e, por fim, desenvolver planos detalhados para garantir que as estratégias sejam implementadas;

- é uma atitude, ou seja, é mais do que exercício intelectual; e

\section{deve gerar a ligação entre planos estratégicos, programas de médio prazo, orçamentos de curto prazo e planos operacionais.}

A conexão entre o longo prazo e o curto, associando questões estratégicas a táticas, constitui elemento de relevância para o desenvolvimento do sistema de planejamento como um todo. Convém evitar o processo etéreo (falta de contato com a realidade das empresas) ou, no outro extremo, um processo exclusivamente tático, o qual deixa de levar em conta elementos estratégicos na empresa. Ambas 
as abordagens deixam de proporcionar o equilíbrio necessário ao processo, gerando insatisfações não apenas para os usuários, mas também para os pesquisadores do tema.

É curioso que uma das críticas mais severas de Mintzberg (1994, pp. 254-255), quanto aos planejadores estratégicos, refere-se ao seu distanciamento dos detalhes do dia-a-dia no processo de formulação de estratégias, com a certeza de que podem ser informados formalmente, ou seja, pelos sistemas de informações factuais. Essa crítica é tão mais valiosa quanto a entidade deixar de disponibilizar aos gestores informações sobre o dia-a-dia de que só a contabilidade gerencial pode dispor. Oliveira (1985), por sua vez, divide as principais falhas mais comuns do planejamento estratégico da seguinte forma: (1) antes do início da elaboração; (2) durante a elaboração; e (3) durante a implementação. Dentre as falhas no início da elaboração, destaca-se a "não preparação do terreno para o planejamento estratégico na empresa', mais especificamente a 'não esquematização do sistema de controle e avaliação do planejamento estratégico': “[...] é fundamental que o executivo estabeleça os critérios e parâmetros, bem como o sistema de informações necessárias para o adequado controle e avaliação do planejamento estratégico" (Oliveira, 1985, p. 35). Levando em conta o comentário do autor, o sucesso do planejamento estratégico depende do controle e da avaliação que ocorrem a partir da existência das ferramentas da contabilidade gerencial, no caso referindo-se ao orçamento e ao controle orçamentário. É nesse sentido que a adequação da contabilidade gerencial proporcionaria apoio necessário ao processo de planejamento como um todo.

Shank e Govindarajan (1997) reforçam a visão apresentada, ao considerar que a administração é processo cíclico que envolve quatro fases:

. Formular estratégias.

. Comunicar estas estratégias a toda a organização.

. Desenvolver e pôr em prática táticas para implementar as estratégias por toda a organização.

\section{- Desenvolver e implementar controles para monitorar as etapas da implementação e depois o sucesso no alcance das metas estratégicas.}

Como se percebe, a conexão entre o planejamento estratégico e o tático é enfatizada pelos autores numa preocupação futura no sentido de viabilizar a aplicabilidade do primeiro, sendo a contabilidade gerencial da entidade a fonte de informação para que isso seja possível. Para atender à demanda acima, o orçamento, instrumento tático dos gestores, deve conter (Welsch et al., 1988): premissas, plano 
de marketing, plano de produção, suprimentos e estocagem, plano de recursos humanos, plano de investimentos, projeção das demonstrações contábeis.

\section{O Relacionamento da Contabilidade Gerencial com o Processo de Planejamento}

A Federação Internacional de Contadores (International Federation of Accountants - IFA), por meio do pronunciamento da International Management Accounting Practice 1 (IFA, 1998), identificou quatro estágios de desenvolvimento da contabilidade gerencial. A cada mudança de estágio, novas condições enfrentadas pelas empresas são absorvidas e adicionadas às tecnologias existentes e ao foco anterior. No apêndice desse pronunciamento, a contabilidade gerencial é definida como:

O processo de identificação, mensuração, acumulação, análise, preparação, interpretação e comunicação de informações (financeiras e operacionais) utilizadas pela administração para planejar, avaliar e controlar internamente uma organização e avaliar o uso de seus recursos, assim como contabilizá-los.

Shank e Govindarajan (1997, p. 5), compartilham essa abordagem, ao considerar que "[...] a contabilidade existe na administração principalmente para facilitar o desenvolvimento e a implementação da estratégia empresarial". Destacam que a informação contábil é base da análise financeira; ao permitir a identificação das estratégias financeiramente exeqüíveis, os relatórios contábeis representam importante ferramenta de comunicação da estratégia em seus pontos fundamentais, permitindo a identificação de qual programa tático poderá ser mais eficaz, no sentido de atingir as metas empresariais; por fim, a contabilidade tem importante papel de monitoramento do desempenho, seja dos gerentes, seja das unidades de negócio, ressaltando-se a relevância dos custos padrões, orçamentos de despesas e planos de lucros anuais, ferramentas que devem ser adaptadas ao contexto estratégico em que se insere a empresa.

Welsch et al. (1988, p. 593), assim como Hansen e Mowen (2000, pp. 30-31), consideram que o sistema de informação contábil está dividido em dois subsistemas principais: financeiro e gerencial. No entanto destacam que esses subsistemas não necessitam ser independentes; idealmente, os dois sistemas deveriam ser integrados e ter bases de dados ligadas. As saídas de cada sistema podem ser usadas como entradas para o outro sistema. Em outras palavras, os autores defendem a integração da base de dados contábil.

Mesmo autores (como Mintzberg, 1994), que criticam o planejamento estratégico, ao reconhecerem a importância deste, referem-se à necessidade de informações que subsidiem tanto a análise anterior à formação das estratégias quanto a 
viabilidade e programação destas. Por sua vez, os dados oriundos da contabilidade são criticados como fonte de informações, seja para analisar o desempenho das empresas (Bracker \& Pearson, 1986, p. 505; Peel \& Bridge, 1998, p. 853), seja para subsidiar o processo de formação de estratégias, porquanto, como afirmam Mintzberg, Ahlstrand e Lampel (2004, p. 60), as informações factuais (entre as quais as informações gerenciais) são:

. [...] freqüentemente limitadas em escopo, carente de riqueza e muitas vezes deixam de abranger importantes fatores não-econômicos e não-quantitativos;

. [...] são demasiado agregadas para seu uso eficaz na formulação de estratégias;

. [...] chegam tarde demais para serem usadas na formulação de estratégia; e

. [...] um volume surpreendente de informações factuais é indigno de confiança.

Diante desse ambiente, o fornecimento de informações torna-se um dos elementos prioritários no processo de tomada de decisão, o que tem provocado mudanças na natureza das informações prestadas pela contabilidade gerencial ao longo dos últimos anos. A contabilidade gerencial surge como importante elemento nesse processo, visto ser ela a fonte de grande parte das informações necessárias para a realização de cada uma das etapas do processo de elaboração do planejamento estratégico. Para Ward (1993, p. 9), “[...] o exercício do planejamento estratégico é elaborado para criar planos que permitiriam alcançar os objetivos da empresa. Esses planos, normalmente, requerem dados significativos da contabilidade gerencial [...]".

Para Horngren, Foster e Datar (2000, pp. 3-4) a contabilidade gerencial facilita o planejamento e controle, fornecendo informações sobre: 1) representação financeira de planos - orçamento; 2) registro e classificação contábil das transações - sistema contábil; e 3) comparação entre o que foi orçado e o real relatórios de desempenho. Esses autores são de opinião que um sistema de controle gerencial somente poderá ser efetivo, quando for consistente com as metas e as estratégias da organização.

\section{Atributos da Estrutura da Contabilidade Gerencial de uma Entidade}

A caracterização da contabilidade gerencial por meio de seus atributos é demanda importante para a estruturação deste trabalho. Como apoio teórico para tal, foi utilizado o trabalho desenvolvido por Moores e Yuen (2001, p. 355), que leva em conta dois tipos de atributos do sistema de contabilidade gerencial. Consideram eles que os atributos relevantes podem ser aglutinados em dois grupos: 
seleção e apresentação da informação, sugeridas a partir da Statement of Accounting Concept 3 (SAC 3).

A seleção inclui os elementos que correspondem às 'dimensões de conteúdo' ou 'ferramentas utilizadas' pela contabilidade. Por sua vez, tendo em consideração que as organizações, dependendo de estratégias, estruturas ou estilos, podem ser diferentes, a apresentação da informação leva em conta alguns atributos, tais como nível de agregação, integração, escopo e tempestividade. De maneira detalhada, as variáveis que compõem os atributos podem ser analisadas a partir do Quadro 1, a seguir.

\section{Quadro 1: Variáveis dos Atributos Utilizadas na Pesquisa}

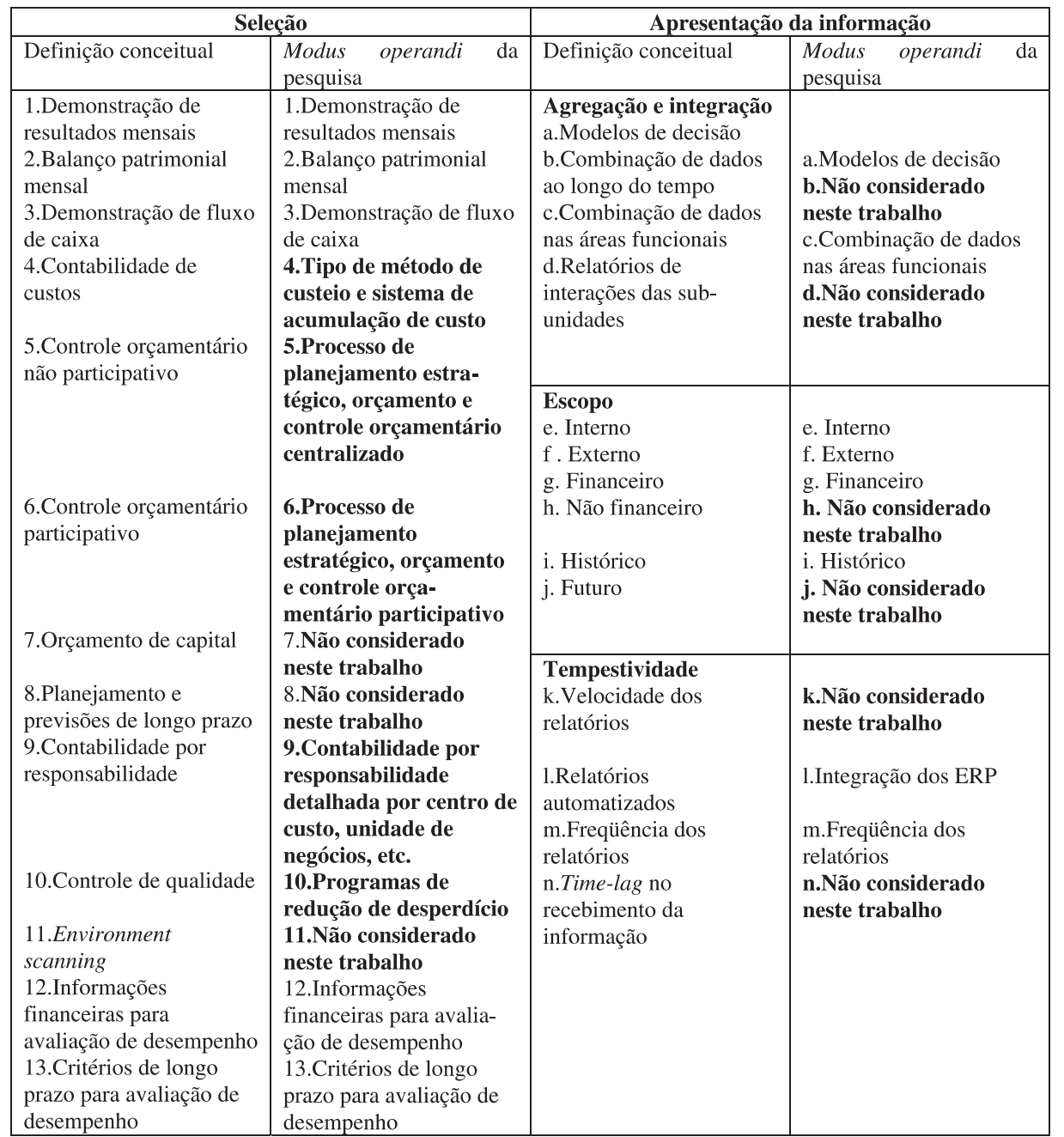

Fonte: Adaptado de Moores e Yuen (2001, p. 355). 
Algumas variáveis incluídas no estudo de Moores e Yuen (2001) deixaram de ser utilizadas nesta pesquisa pelos motivos expostos a seguir (Quadro 1), sendo:

- Orçamento de capital e Escopo futuro estão incluídos nas variáveis que se pretende relacionar no processo de planejamento. Dessa maneira, elimina-se um tipo de correlação não desejada.

. Environment scanning, por ser por demais específico e não considerado útil para o foco da pesquisa proposta, voltada para o lado decisório interno da entidade; $\mathrm{e}$

Informações não financeiras, relatórios de interações das subunidades, combinação de dados ao longo do tempo, velocidade dos relatórios e time-lag dos relatórios pela dificuldade em obter respostas adequadas e que podem ser comparadas.

\section{Delineamento da Pesquisa e Questóes Metodológicas}

A estrutura da pesquisa foi baseada na abordagem desenvolvida por Henry (1990), que relaciona a natureza do estudo, a população e o plano amostral, a coleta de dados e o instrumento às variáveis de interesse na pesquisa e à análise estatística.

\section{Natureza do Estudo}

Neste sentido, esta pesquisa de campo tem o caráter descritivo.

\section{População e Plano Amostral}

Na população foram incluídas organizações que operam no país, sejam elas multinacionais, nacionais, estatais ou privadas, de todos os estados da Federação. Com relação à definição do que caracteriza a empresa de médio porte, foi utilizado o conceito do Banco Nacional de Desenvolvimento Econômico e Social (BNDES) que considera empresa de porte médio aquela cujo faturamento anual seja superior a US\$18 milhões. A base de dados da revista brasileira Melhores e Maiores foi utilizada como a fonte de informação sobre as organizações na definição da população a ser estudada. No total foram identificadas 2.281 organizações caracterizadas como sendo de médio ou grande portes; a receita 
total deste grupo chegou a US\$502 bilhões em 2001. A população foi combinada em sete setores (Quadro 2). Para complementar os estratos populacionais, os setores foram segmentados por faixas de faturamento anual em dólar como referência ao porte da entidade.

\section{Quadro 2: Segmentação da População por Setor}

\begin{tabular}{|c|c|c|}
\hline $\begin{array}{c}\text { Códigos por } \\
\text { setor } \\
\text { resumido }\end{array}$ & $\begin{array}{c}\text { Códigos por } \\
\text { setor } \\
\text { originais } \\
\end{array}$ & Título \\
\hline \multirow[t]{2}{*}{1} & 2 & Atacadista e comércio exterior \\
\hline & 5 & Varejo \\
\hline \multirow{16}{*}{2} & 1 & Alimentos \\
\hline & 3 & Automóvel \\
\hline & 4 & Cerveja e refrigerantes \\
\hline & 6 & Têxtil e confecções \\
\hline & 7 & Construção civil \\
\hline & 8 & Elétrico-eletrônico \\
\hline & 9 & Farmacêutico \\
\hline & 10 & Higiene, limpeza e cosméticos \\
\hline & 12 & Materiais para construção civil \\
\hline & 13 & Mecânico \\
\hline & 14 & Mineração \\
\hline & 15 & Papel e celulose \\
\hline & 16 & Plástico e borracha \\
\hline & 17 & Substância química e petroquímico \\
\hline & 21 & Siderurgia e metalurgia \\
\hline & 22 & Tecnologia e informática \\
\hline 3 & 11 & Instituições financeiras \\
\hline 4 & 23 & Telecomunicações \\
\hline 5 & 19 & Serviços públicos \\
\hline \multirow{3}{*}{6} & 18 & Serviços - outros \\
\hline & 20 & Transportes \\
\hline & 24 & Comunicações \\
\hline 7 & 25 & Vários outros \\
\hline
\end{tabular}

No trabalho de campo, a amostra foi definida de maneira probabilística, estratificada em termos das faixas de faturamento anual em dólar, considerandose a margem de erro de $10 \%$ e nível de significância de $95 \%$. Foram obtidas respostas de 119 entidades, identificadas levando em conta abordagem randômica, através dos números aleatórios, utilizando os recursos da planilha eletrônica EXCEL, considerando tanto o setor como o porte. 


\section{Coleta de Dados e Instrumento}

Por meio de um levantamento amostral, realizou-se a coleta de dados, tendo sido o questionário o instrumento para obtenção dos dados, pois pode ser utilizado com objetividade, abrangência de tratamento e não invalida a entrevista pessoal, que foi realizada complementarmente. Na construção do questionário, foram considerados os fatores seguintes: (i) quais elementos pesquisar (detalhamento de componentes que poderiam afetar a formulação das perguntas); e (ii) análise de consistência das perguntas (sucessão de perguntas, saltos e verificação das metas foram avaliados no pré-teste). Todos os questionários foram enviados através de e-mail para o principal executivo financeiro da empresa, ocorrendo três situações: (i) autopreenchimento; (ii) autopreenchimento com a realização de entrevista para esclarecimento de alguns pontos; e (iii) realização de entrevista para preenchimento conjunto (pesquisador e respondente). No total, $30 \%$ das empresas que responderam à pesquisa foram entrevistadas. A pesquisa de campo foi desenvolvida de abril a novembro de 2002, contando com três entrevistadores que mantiveram o contato com as organizações.

\section{Variáveis de Interesse na Pesquisa}

O esforço da pesquisa está centrado na análise da associação entre o perfil de atributos da contabilidade gerencial e o seu perfil de planejamento da empresa. Para tanto, uma vez identificados os atributos da contabilidade gerencial, agrupados em três diferentes clusters, os perfis de planejamento de cada cluster foram obtidos. Dessa maneira, as variáveis consideradas foram as seguintes.

\section{Na Contabilidade Gerencial}

As variáveis que indicam os atributos da contabilidade gerencial, descritos na revisão da literatura, foram apresentadas no Quadro 1.

Para a aplicação da técnica de cluster analysis, tais variáveis foram submetidas a uma transformação, a partir de uma abordagem dicotômica (1 para identificar a existência e 0 para a sua ausência). Dessa maneira, as empresas foram separadas em três diferentes grupos, de acordo com o seu perfil. 


\section{No Planejamento}

As variáveis foram tratadas a partir da técnica Analytic Hierarchy Process AHP (Saaty, 1996). Para cada variável foi atribuída pontuação ordinal dentro do intervalo de 1 a 5: quanto maior a importância e complexidade, maior a nota, levando em conta as seguintes opções, sendo preferenciais as duas primeiras, e a terceira só utilizada quando as duas primeiras não foram possíveis:

- do relativamente mais básico (nota 1) para o mais complexo/completo (nota 5, no conceitual, recurso, ou atualiza senso);

- da precedência natural (nota 1) para o último em ser obtido (nota 5, no conceitual); ou

- do mínimo (nota 1) requerido ao mais desejável (nota 5) da perspectiva conceitual.

Nos casos em que os elementos não foram encontrados, o zero será o identificador e será apurada a soma de pontos que cada empresa obtiver.

As variáveis apresentadas na revisão da literatura e tratadas no trabalho de acordo com o AHP e suas respectivas pontuações foram:

. Planejamento estratégico: visão ( 1 ponto), missão ( 2 pontos), cenários ( 3 pontos), objetivos de longo prazo (4 pontos) e planos operacionais de longo prazo (5 pontos). A pontuação máxima que uma entidade poderia obter seria 15.

- Orçamento (Tático): premissas (1 ponto), plano de marketing (2 pontos), plano de produção, suprimentos, estocagem (3 pontos), plano de recursos humanos (4 pontos), plano de investimentos (4 pontos) e demonstrações contábeis projetadas (5 pontos). A pontuação máxima que uma entidade poderia obter seria 19.

\section{AnÁlise Estatística}

Este estudo utiliza os seguintes recursos estatísticos.

. Estatística descritiva, considerando a mediana, mínimos e máximos.

Análise Multivariada, especificamente a técnica de cluster analysis, com o 
objetivo de segmentar as entidades e identificar diferentes perfis da contabilidade gerencial. Nesse sentido, a técnica a ser utilizada leva em conta a abordagem hierárquica, escala binária, método de aglomeração furthest neighbour, com o objetivo de identificar os três diferentes grupos de empresas em termos de atributos da contabilidade gerencial.

- O teste da mediana, aplicado com o objetivo de analisar os três diferentes aglomerados, sendo as hipóteses, para o nível de significância de 95\%:

. h0: não existe diferença entre as medianas, ou seja, não existe relação entre o perfil de atributos da contabilidade gerencial e o perfil de planejamento da entidade; $\mathrm{e}$

. h1: existe diferença entre as medianas, ou seja, existe relação entre o perfil de atributos da contabilidade gerencial e o perfil de planejamento da entidade.

\section{ANÁlISE dOS DAdOS}

A análise dos dados foi feita a partir dos três diferentes clusters: quanto maior o respectivo tamanho em relação ao número de participantes $(6,38$ e 75 de um total de 119, respectivamente), maior a aderência em termos dos atributos da contabilidade gerencial no que se refere ao modelo consolidado por Moores e Yuen (2001). Significa dizer que, predominantemente, as empresas dispõem da estrutura de contabilidade gerencial necessária. Com relação à tese apresentada, referente à associação da contabilidade gerencial com o processo de planejamento, observa-se que ela procede (Tabelas 1 e 2).

Tabela 1: Teste da Mediana

\begin{tabular}{rrrr}
\hline & PE & ORC & PE + ORC \\
\hline Casos & & & \\
Mediana & 119 & 119 & 119 \\
Qui-Quad. & 2,434 & 15,0 & 24,0 \\
$\%$ de significância & 0,296 & 7,873 & 7,544 \\
\hline
\end{tabular}


Tabela 2: Clusters dos Atributos da Contabilidade Gerencial e Perfis de Planejamento Estratégico (PE) e Orçamento (ORC)

\begin{tabular}{rrrr}
\hline & PE & ORC & PE + ORC \\
\hline Cluster 1 & \multicolumn{3}{c}{} \\
\hline Casos & 6 & 6 & 6 \\
Mediana & 5,5 & 9,0 & 17,5 \\
Mínimo & 3,0 & 0,0 & 3,0 \\
Máximo & 15,0 & 19,0 & 29,0 \\
\hline Cluster 2 & & & 38 \\
Casos & 38 & 38 & 20,0 \\
Mediana & 10,0 & 13,0 & 0,0 \\
Mínimo & 0,0 & 0,0 & 34,0 \\
Máximo & 15,0 & 19,0 & 75 \\
\hline Cluster 3 & & & 26,0 \\
Casos & 75 & 75 & 4,0 \\
Mediana & 10,0 & 18,0 & 34,0 \\
Mínimo & 3,0 & 0,0 & 119 \\
Máximo & 15,0 & 19,0 & 24 \\
\hline Total $\quad$ & & 0,0 \\
\hline Casos & 119 & 119 & 34,0 \\
Mediana & 10,0 & 15,0 & \\
Mínimo & 0,0 & 0,0 & 19,0 \\
Máximo & 15,0 & & \\
\hline
\end{tabular}

Analisando as características das empresas a partir do porte e do setor da economia, pode-se dizer (Tabelas 3 e 4 ) o seguinte:

Tabela 3: Distribuição de Clusters por Setores

\begin{tabular}{|c|c|c|c|c|c|}
\hline Setor & Código & Cluster 1 & Cluster 2 & Cluster 3 & Total \\
\hline Comércio exterior e atacado & 1 & 1 & 4 & 11 & 16 \\
\hline Indústria em geral & 2 & 2 & 16 & 37 & 55 \\
\hline Instituições financeiras & 3 & 0 & 4 & 10 & 14 \\
\hline Telecom serviços & 4 & 0 & 1 & 3 & 4 \\
\hline Serviços públicos & 5 & 2 & 6 & 4 & 12 \\
\hline Outros serviços & 6 & 0 & 7 & 10 & 17 \\
\hline Diversos & 7 & 1 & 0 & 0 & 1 \\
\hline Total & & 6 & 38 & 75 & 119 \\
\hline \multicolumn{6}{|l|}{ Em \% } \\
\hline Comércio exterior e atacado & & $17 \%$ & $11 \%$ & $15 \%$ & $13 \%$ \\
\hline Indústria em geral & & $33 \%$ & $42 \%$ & $49 \%$ & $46 \%$ \\
\hline Instituições financeiras & & $0 \%$ & $11 \%$ & $13 \%$ & $12 \%$ \\
\hline Telecom serviços & & $0 \%$ & $3 \%$ & $4 \%$ & $3 \%$ \\
\hline Serviços públicos & & $33 \%$ & $16 \%$ & $5 \%$ & $10 \%$ \\
\hline Outros serviços & & $0 \%$ & $18 \%$ & $13 \%$ & $14 \%$ \\
\hline Diversos & & $17 \%$ & $0 \%$ & $0 \%$ & $1 \%$ \\
\hline Total & & $100 \%$ & $100 \%$ & $100 \%$ & $100 \%$ \\
\hline
\end{tabular}


Tabela 4: Distribuição de Clusters por Faturamento - em US\$

\begin{tabular}{|c|c|c|c|c|c|}
\hline & Código & Cluster 1 & Cluster 2 & Cluster 3 & Total \\
\hline Até 50 milhões & 1 & 4 & 7 & 10 & 21 \\
\hline$>50$ e $<100$ milhões & 2 & 0 & 6 & 10 & 16 \\
\hline$>100$ e $<250$ milhões & 3 & 0 & 7 & 10 & 17 \\
\hline$>250$ e $<500$ milhões & 4 & 1 & 4 & 11 & 16 \\
\hline$>500 \mathrm{e}<1.000$ milhões & 5 & 0 & 8 & 12 & 20 \\
\hline$>1.000$ e $<3.000$ milhões & 6 & 1 & 5 & 17 & 23 \\
\hline$>3.000 \mathrm{e}<30.000$ milhões & 7 & 0 & 1 & 5 & 6 \\
\hline Total & & 6 & 38 & 75 & 119 \\
\hline Até 50 milhões & & $67 \%$ & $18 \%$ & $13 \%$ & $18 \%$ \\
\hline$>50$ e $<100$ milhões & & $0 \%$ & $16 \%$ & $13 \%$ & $13 \%$ \\
\hline$>100$ e $<250$ milhões & & $0 \%$ & $18 \%$ & $13 \%$ & $14 \%$ \\
\hline$>250$ e $<500$ milhões & & $17 \%$ & $11 \%$ & $15 \%$ & $13 \%$ \\
\hline$>500 \mathrm{e}<1.000$ milhões & & $0 \%$ & $21 \%$ & $16 \%$ & $17 \%$ \\
\hline$>1.000 \mathrm{e}<3.000$ milhões & & $17 \%$ & $13 \%$ & $23 \%$ & $19 \%$ \\
\hline$>3.000 \mathrm{e}<30.000$ milhões & & $0 \%$ & $3 \%$ & $7 \%$ & $5 \%$ \\
\hline Total & & $100 \%$ & $100 \%$ & $100 \%$ & $100 \%$ \\
\hline
\end{tabular}

- Quanto aos setores, a predominância das indústrias, no total da amostra, é mantida em cada cluster. Nota-se que, em termos de participação relativa de empresas, existe equiparação deste setor com a área de serviços públicos no cluster 1. Adicionalmente, nenhuma instituição financeira aparece no cluster 1.

. No que se refere ao porte das empresas, nota-se que as empresas do cluster 1 são predominantemente as de relativo menor porte, ao passo que não existem nele empresas de grande porte. Essa conclusão é consistente com outros estudos feitos no país e no exterior.

Foi aplicado o teste da mediana (Tabela 1), com o objetivo de, ao olhar a amostra como um todo, percebendo os três diferentes clusters, indicar se existem diferenças significativas entre as medianas das três amostras independentes. O teste revela o seguinte.

. Para o planejamento estratégico, a hipótese h0 foi aceita (0,296 versus 0,05$)$, indicando que as amostras não são significativamente diferentes. Dessa maneira, pode-se concluir que, isoladamente, o planejamento estratégico não é influenciado pela contabilidade gerencial.

. Para o orçamento, h0 foi rejeitada $(0,02$ versus 0,05$)$, indicando que as amostras são significativamente diferentes. Como conseqüência, aceita-se h1, o que leva a concluir que existe influência dos atributos da contabilidade gerencial sobre o orçamento. 
- Para a junção do planejamento estratégico e do orçamento, construto que tenta abarcar a existência de ambos nas entidades, h0 foi rejeitada $(0,02$ versus $0,05)$, indicando que as amostras são significativamente diferentes. Como consequiência, aceita-se h1, o que leva a concluir que existe influência dos atributos da contabilidade gerencial, quando se fala do relacionamento dos instrumentos de planejamento como um todo.

São apresentadas, a seguir, algumas características dos clusters encontrados.

. Cluster 1.É o que indica menor aderência da contabilidade gerencial em relação ao modelo consolidado por Moores e Yuen (2001), tendo seis empresas dentro da amostra e apresentando:

. Menor pontuação da mediana para o perfil de planejamento estratégico (5,5 versus 10 da amostra), com diferenciação em relação aos demais clusters.

- Menor pontuação da mediana para o perfil do orçamento ( 9 versus 15 da amostra), indicando significativa diferenciação em relação aos demais clusters.

Neste cluster, o pequeno número de empresas contida na amostra traz impacto limitativo em termos de conclusões possíveis, como será indicado mais à frente.

. Cluster 2. Contém trinta e oito empresas e apresenta:

- Pontuação da mediana para o planejamento estratégico superior à do cluster $1(10$ versus 5,5$)$ e igual à do cluster $3(10$ versus 10$)$.

. Pontuação da mediana para o orçamento significativamente superior à do cluster 1 (13 versus 9), o que indica maior aderência ao arcabouço conceitual neste cluster. Os dados podem significar que, uma vez existindo condições mínimas de estrutura nos atributos da contabilidade gerencial, a disponibilização dos instrumentos é mais significativa no orçamento do que no planejamento estratégico.

. Cluster 3. Este é o cluster que incorpora o maior número de empresas (75), com maior aderência de atributos ao modelo utilizado. Devem ser considerados os resultados:

. Pontuação da mediana para o planejamento estratégico estável em relação à do cluster 2 (10 versus 10).

. Pontuação da mediana para o orçamento significativamente superior à dos clusters 1 e 2 (18 versus 13 e 9, respectivamente), indicando que, quanto mais aderente ao modelo, maior o potencial de disponibilização da plenitude dos conceitos da ferramenta pela empresa. 
Em termos totais, pode ser observado que existe razoável gap entre a pontuação máxima possível de ser obtida pelas empresas no planejamento estratégico (10 versus 15) e no orçamento (15 versus 19), o que indica que os artefatos não estão sendo disponibilizados da maneira como o referencial teórico propõe. Observa-se que tal gap, no que se refere ao planejamento estratégico é maior no cluster 1 , sendo reduzido nos clusters 2 e 3 . Por sua vez, no que se refere ao orçamento, a maior aderência da contabilidade gerencial ao modelo consolidado por Moores e Yuen (2001) indica crescente aumento da aderência conceitual, significando uma associação mais forte do que aquela entre a contabilidade gerencial e o plano estratégico.

\section{ComentÁrios Finais}

Embora possam ser encontradas diversas menções quanto à associação entre contabilidade gerencial e planejamento estratégico na literatura gerencial, não tem sido possível identificar, nessa mesma literatura, estudos que validem, ou mesmo que refutem essa tese de maneira empírica. Este artigo, ao questionar a existência de associação entre a estrutura de atributos da contabilidade gerencial utilizada nas organizações brasileiras de médio e grande porte e a sua aderência conceitual no desenvolvimento do planejamento, busca, portanto, fornecer subsídios que contribuam para a validação ou refutação da referida tese, possível a partir da disponibilidade do modelo consolidado por Moores e Yuen (2001).

Os resultados decorrentes da análise sinalizam que existe relacionamento entre a estrutura de atributos da contabilidade gerencial e o processo de planejamento das empresas. Foi evidenciado que esse impacto ocorre de maneira não uniforme e mesmo diferenciada no que se refere aos componentes do processo de planejamento, ou seja, o planejamento estratégico e o tático.

Pela análise oferecida percebe-se que o planejamento estratégico pode ser muito afetado até certo patamar de disponibilidade de atributos. A partir daí, a influência da contabilidade gerencial seria menor sobre ele. Por sua vez, a associação da aderência do modelo consolidado por Moores e Yuen (2001) com o orçamento, em cada cluster, é evidenciada, implicando que o instrumento tático tenha mais demanda da contabilidade gerencial do que o planejamento estratégico. Considerando o planejamento como um todo, estratégico e tático, também foi possível perceber a associação da aderência ao modelo utilizado, em cada cluster. 
A disponibilidade de outros trabalhos empíricos certamente trará oportunidades de confronto para se aprofundarem discussões sobre a disponibilidade e forma de utilização dos artefatos da contabilidade gerencial.

\section{Artigo recebido em 15.04.2005. Aprovado em 19.07.2005.}

\section{ReferênCias Bibliográficas}

Andersen, T. J. (2000).

Strategic planning, autonomous actions and corporate performance. Long Range Planning, 33(2), 184-200.

Ansoff, H. I.,

Declerck, R. P., \&

Hayes, R. L. (Eds.). (1976).

From strategic planning to strategic management. London: Jown Wiley \& Sons.

Ansoff, H. I. (1991).

A nova estratégia empresarial. São Paulo: Atlas.

Ansoff, H. I. (1997).

The state of practice in planning systems. Sloan Management Review, 18(2), 1-24.

Armstrong, J. S. (1982).

The value of formal planning for strategic decisions: review of empirical research. Strategic Management Journal, 3(3), 197-211.

Bracker, J. N., \&

Pearson, J. N. (1986).

Planning and financial performance of small, mature firms. Strategic Management Journal, 7(6), 503-522.
Brock, D. M., \&

Barry, D. (2003).

What if planning were really strategic? Exploring the strategy-planning relationship in multinationals. International Business Review, 12(5), 543-561.

Delmar, F., \&

Shane, S. (2003).

Does business planning facilitate the development of new ventures? Strategic Management Journal, 24(12), 1165-1185.

Fischmann, A. A., \&

Almeida, M. I. R. (1993).

Planejamento estratégico na prática (2a ed.). São Paulo: Atlas.

Glaister, K. W., \&

Falshaw, J. R. (1999).

Strategic planning: still going strong?

Long Range Planning, 32(1), 107-116.

Grant, R. M. (2003).

Strategic planning in a turbulent environment: evidence from the oil majors. Strategic Management Journal, 24(6), 491-517.

Hansen, D. R., \&

Mowen, M. M. (2000).

Cost management: accounting and control (3rd ed.). Mason, Ohio: SouthWestern College Publishing. 
Henry, G. (1990).

Practical sampling. London: Sage.

Horngren, C. T.,

Foster, G., \&

Datar, S. M. (2000).

Cost accounting: a managerial emphasis (10th ed.). New Jersey: Prentice-Hall.

International Federation of Accountants - IFA (1998, March).

International Management

Accounting Practice 1. Recuperado de http://mmm.mia.org.my/handbook/ guide/IMAP/imap_1.htm

Liedtka, J. (2000).

Strategic planning as a contributor to strategic change: a generative model. European Management Journal, 18(2), 195-206.

Mintzberg, H. (1994).

The rise and fall of strategic planning. London: Prentice Hall.

Mintzberg, H.,

Ahlstrand, B., \&

Lampel, J. (2004).

Safári da estratégia: um roteiro pela selva do planejamento estratégico. Porto Alegre: Bookman.

Moores, K., \&

Yuen, S. (2001).

Management accounting systems and organizational configuration: a life-cycle perspective. Accounting, Organizations and Society, 26(4/5), 351-389.
O'Regan, N., \&

Ghobadian, A. (2002).

Formal strategic planning: the key to effective business process management? Business Process Management Journal, 8(5), 416-429.

Oliveira, D. P. R. (1985).

As principais causas do fracasso do planejamento estratégico nas empresas. Revista do IMES, 3(17), 32-38.

Oliveira, D. P. R. (1994).

Planejamento estratégico: conceitos, metodologia e práticas (8a ed.). São Paulo: Atlas.

Pearce, J. A. II,

Freeman, E. B., \&

Robinson, R. B., Jr. (1987).

The tenuous link between formal strategic planning and financial performance. The Academy of Management Review, 12(4), 658-675.

Peel, M. J., \&

Bridge, J. (1998).

How planning and capital budgeting improve SME performance. Long Range Planning, 31(6), 848-856.

Rogers, P. R., \&

Bamford, C. E. (2002).

Information planning process and strategic orientation: the importance of fit in high-performing organization. Journal of Business Research, 55(3), 205-215.

Saaty, T. (1996).

Multi-criteria decision making: the analytic hierarchy process. Pittsburg, PA: RWS Publications. 
Shank, J. K., \&

Govindarajan, V. (1997).

A revolução dos custos: como reinventar e redefinir sua estratégia de custos para vencer em mercados crescentemente competitivos ( $2 \mathrm{a}$ ed.). Rio de Janeiro: Campus.

Sharplin, A. (1985).

Strategic management. New York: McGraw-Hill.
Steiner, G. A. (1979).

Strategic planning. New York: The Free Press.

Ward, K. (1993).

Strategic management accounting. Oxford: Butterworth-Heinemann.

Welsch, G. A.,

Hilton, R. W., \&

Gordon, P. N. (1988).

Budgeting: profit planning and control (5th ed.). Englewood Cliffs: Prentice-Hall. 